\title{
O TRABALHO DOCENTE E SUA RELAÇÃO COM O MAL-ESTAR
}

Ademir Henrique Manfre

PPGE/FCT/Universidade Estadual Paulista - UNESP - Presidente Prudente - SP. E-mail: ademirmanfre@yahoo.com.br. FAPESP

\section{RESUMO}

Este artigo aborda a temática mal-estar docente na educação. Trata-se de um recorte que realizamos de nosso trabalho de pesquisa desenvolvido no doutorado em educação cujo objetivo geral é investigar em que consiste o fenômeno mal-estar docente, numa tentativa de ressignificar oque acontece na escola e fora dela por meio da experiência formativa. Para tanto, realizamos um levantamento bibliográfico em teses e dissertações de mestrado no banco de dados do Portal CAPES com o objetivo de compreender como a temática vem sendo debatida no campo teórico educacional brasileiro. Neste texto, apresentamos algumas leituras que realizamos do material selecionado, apontando algumas indicações da pesquisa. O referencial teórico adotado foi baseado nas reflexões teóricas desenvolvidas por Adorno e Walter Benjamin.

Palavras-chave: educação, semiformação, mal-estar docente, formação docente, experiência.

\section{INTRODUÇÃO E OBJETIVOS}

Este artigo aborda a temática mal-estar docente no campo escolar. Para tanto, objetiva:

- investigar em que consiste o fenômeno mal-estar docente, clarificando o seu sentido;

-analisar quais relações se podem estabelecer entre mal-estar docente, formação docente e semiformação;

-investigar, a partir de Benjamin e Adorno, os impactos das mudanças tecnológicas sobre a subjetividade dos indivíduos e o que disso decorre para o empobrecimento da experiência.

\section{METODOLOGIA}

Como metodologia de pesquisa, optamos pela pesquisa bibliográfica onde elegemos o portal CAPES para levantamento de teses e dissertações de mestrado. O recorte temporal compreendeu o período situado entre 2001 e 2010. No total, selecionamos 21 trabalhos para análise e discussão.

\section{DISCUSSÃO}

1. A PRODUÇÃO DO MAL-ESTAR DOCENTE E A ESCOLA

Nos últimos vinte anos vêm aumentando significativamente os estudos sobre a temática mal-estar docente. Muitas pesquisas têm se avolumado em torno das repercussões dos riscos 
físicos causados pela profissão docente, principalmente os relacionados com o estresse, os problemas de voz, a violência escolar, os problemas de indisciplina dos alunos, síndromes, medos, angústias, sofrimentos, dentre outros.

Já em 1981, a OIT - Organização Internacional do trabalho - considerou o trabalho docente como uma profissão de riscos físicos e mentais significativos.

Um dos pioneiros a trabalhar com a temática mal-estar docente foi o espanhol José Manoel Esteve, principalmente com a primeira publicação da obra "O mal-estar docente: a sala de aula e a saúde dos professores" em 1987.

Para o pesquisador acima referido, o mal-estar docente é definido como sendo "[...] os efeitos permanentes de caráter negativo que afetam a personalidade do professor como resultado das condições psicológicas e sociais em que se exerce a docência”. (ESTEVE, 1999, p. 25).

Esteve (1999) concebe os indicadores do mal-estar docente em fatores primários e secundários. Os fatores primários são aqueles que atuam diretamente na docência gerando tensões negativas no seu trabalho cotidiano. Os mesmos são relacionados "ao clima da sala de aula, destacando, para relacioná-lo com os períodos de formação inicial e contínua do professorado, o estudo da atuação do professor em sala de aula". (ESTEVE, 1999, p. 47).

Os fatores secundários são os relacionados ao contexto do exercício pedagógico, como a modificação no papel do professor; a função docente no campo das contradições, dentre outros. Esteve (1999, p. 27) observa que esses fatores podem atuar isolados, mas quando "se acumulam, influem fundamentalmente sobre a imagem que o professor tem de si mesmo e de seu trabalho profissional, gerando uma crise de identidade...".

Kobori (2010) nos apresenta um cenário em que focaliza algumas das ações e desafios enfrentados pelos educadores no cotidiano da escola. O trabalho docente passa a ter diversas dimensões que se agudizam, pela condição de isolamento como muitas vezes é realizado, onde o professor é cobrado pelo seu desempenho e, ao mesmo tempo, se exige pelas suas dificuldades frente a um contexto para o qual não foi preparado, situação que leva ao mal-estar. Nessa situação, o estresse é muito alto para o professor, que não encontra consenso para efetivar seu papel, conclui a autora. Outro aspecto assinalado pela autora se inscreve na perda de status do ser professor. Dessa forma, se instaura o mal-estar docente, conclui Kobori (2010).

Outro indicador ligado ao mal-estar docente refere-se à violência nas escolas.

Segundo Sthehl (2010) este fator possui uma repercussão fortíssima no desempenho do professor e está cada vez mais banalizado nas escolas. Dessa maneira, a violência cresce nas 
escolas e estabelecem-se assim impactos negativos sobre o trabalho do professor, num processo de aumento contínuo do mal-estar docente, levando-o ao esgotamento. Outro fator gerador do mal-estar docente refere-se à contradição entre o ideal da profissão e a atuação concreta que ele consegue desempenhar.

Assim, observa Weber (2009) diante do sofrimento e do mal-estar docente é preciso penetrar no espaço onde se efetiva o trabalho do educador e encontrar soluções práticas e eficientes para sua resolução.

Como apontado anteriormente, o "adoecimento" do professor é foco de vários estudos que buscam compreendê-lo e associá-lo às transformações sociais, políticas, econômicas e culturais na atualidade. Dentre as queixas registradas e que favorecem a produção do mal-estar docente, de acordo com as pesquisas aqui apontadas, podemos citar os transtornos de ansiedade, problemas de saúde mental, afecções vocais, problemas de voz, desgaste do aparelho músculoesquelético, depressões, síndromes do pânico, dentre outros.

Nessa perspectiva do adoecimento do professor, os pesquisadores ainda indicam outras queixas: dor de garganta, dor nas pernas, cansaço mental, rouquidão, distúrbios psíquicos, problemas visuais, nervosismo, angústia, esgotamento, irritabilidade, alergias, desordens gastrintestinais, artrites, asma. Mal-estar aqui, segundo os pesquisadores, é identificado como sinônimo de dor, doença.

O quadro que se apresenta não é muito animador. As pesquisas retratam um profissional retalhado, esquecido, sofredor, obcecado. Essas denominações ilustram o mal-estar que passa a ser vivenciado pelo professor diante das tensões, conflitos e decepções da profissão docente.

Pela análise que realizamos do material selecionado para este estudo, há um elemento que se repete nas pesquisas quando são apontados os efeitos do trabalho docente sobre o corpo desse profissional: apenas os efeitos negativos da atividade pedagógica são ressaltados.

Além dos aspectos já mencionados, Sampaio (2008) elege algumas estratégias para se evitar o mal-estar sofrido pelo professor na escola. A primeira delas é que o professor deve desenvolver competências e estratégias para gerenciar o mal-estar cotidiano. Kobori (2010) afirma que o professor deve desenvolver a capacidade de adaptação aos diferentes contextos. Leão (2003) observa que o professor deve desenvolver a capacidade de superação dos potenciais estressores. Lapo e Bueno (2003) afirmam que o docente deve ser resiliente. Fonseca (2009) afirma que o professor deve desenvolver a motivação no processo educativo. Niches (2010) e 
Gonçalves (2008) afirmam que o professor deve propiciar o bem-estar em detrimento do malestar.

Fica nítido nessa exposição que quase nada é apontado sobre a subjetividade do professor. Ressaltam-se apenas os aspectos visuais, aparentes do mal-estar vivenciado pelo professor. Também fica claro nas pesquisas analisadas que o bem-estar seria a solução para o mal-estar vivenciado pelo professor na escola.

Apenas a insatisfação, o desgaste, o esgotamento físico e mental dos professores em sua ação cotidiana junto à escola são ressalvados. Nada é apontado sobre os desejos, a percepção dos professores, a singularidade das produções subjetivas. Nada é apontado sobre a formação dos professores. Apenas os aspectos mais instrumentais são ressaltados.

A nosso ver, trata-se de uma análise superficial que estaria mais presa a ressaltar os aspectos internos à própria escola, sem se atentar de forma elaborada e sistemática para aquilo que extrapola o contexto escolar.

Nesse sentido, propomos um outro olhar sobre o fenômeno mal-estar docente na tentativa de ressignificar o que acontece na escola e fora dela. Para tanto, recorremos às reflexões filosóficas de Adorno e Walter Benjamin com relação à temática da experiência para pensarmos a discussão do mal-estar docente. Que relação podemos estabelecer entre mal-estar docente e semiformação? Que relação podemos estabelecer entre mal-estar docente e pobreza da experiência? São algumas das questões que nos guiam e nos levam a pensar o mal-estar docente pela via da experiência.

\section{O MAL-ESTAR DOCENTE E A (IM)POSSIBILIDADE DA EXPERIÊNCIA}

Em linguagem popular, experiência, enquanto efeito ou ato de experimentar, significa prática de vida. Em outro sentido, experiência é um sinônimo de competência social ou técnica, no sentido de se possuir habilidade, prática adquirida com a dedicação constante a uma profissão, a arte ou oficio.

Com o advento da modernidade, experiência significa prova, demonstração, tentativa, modelo. Esta concepção equivale ao processo de experimentação enquanto método científico que consiste em observar um fenômeno natural, utilizando-se de instrumentos, aparatos que permitem ampliar o conhecimento que se tenha das manifestações ou leis que regem um fenômeno, tendo como modelo o cálculo matemático e o funcionamento mecanizado do relógio.

Em Benjamin (1994a e 1994b), a experiência (Erfahrung) toma outros sentidos. 
As manifestações da experiência rigorosamente comunitárias (primitivas) passavam necessariamente pelo rito (conjunto de expressões, sentidos, ações, gestos que enquadra as maneiras de expressão individual numa rede de significantes coletivos), modos de contar, modos de produzir a cultura, hábitos, caracterizando-se numa configuração mediada de experiência que se torna aceita dentro do grupo, predispondo a todo um conjunto de alianças, projetos, ações partilhadas e códigos de valores compartilhados.

À luz do que o próprio Benjamin (1994a e 1994b) sinaliza em seus textos, esse tipo de experiência se torna empobrecida nas sociedades modernas, onde as pessoas vivem atomizadas em seus pequenos mundos, enquadradas nos ambientes funcionais da arquitetura contemporânea, ao mesmo tempo em que estão virtualmente conectadas com o mundo via internet. A vivência corporal, própria das comunidades ritualísticas, criava outras formas de experiência mais íntimas, interiorizadas, cujo vínculo indissolúvel com o passado era efetivo, onde os rituais eram vivenciados e transmitidos de geração a geração ${ }^{1}$.

$\mathrm{Na}$ modernidade, dirá Benjamin (1994a), ao contrário, configuram-se expressões de comportamento cada vez mais individualizados, cada indivíduo torna-se independente um do outro, prevalecendo microssistemas que apenas se tocam tangencialmente. Para Benjamin (1994a), os rituais de iniciação, as festas folclóricas e outros dispositivos sociais antigos desapareceram. A sociedade atual, repleta de comunicações eletrônicas e tecnológicas instantâneas, isola as pessoas em seus redutos, impedindo outro tipo de contato que não o da instrumentalidade. Mesmo as ligações afetivas, assim como as comerciais e acadêmicas, inseremse no contexto virtual, mediatizadas pelo instantâneismo, pelo utilitarismo.

O conceito de experiência (Erfahrung) em Benjamin é complexo, pois opera por oposição ao conceito de vivência (Erlebnis). Ao passo que a vivência (Erlebnis) refere-se às experimentações e ao viver cotidiano do indivíduo particular, experiência (Erfahrung) constela valores e formas de saberes de uma coletividade.

Nos ensaios "Experiência e pobreza" e "O narrador", Benjamin estabelece um jogo entre conceitos, imagens e parábolas para delinear a correspondência entre o declínio da arte de narrar e a nova transformação de um mundo não mais compartilhado como coletividade. Como decorrência dessas proposições o que resta é uma nova barbárie que deve e precisa ser assumida para que o homem moderno possa dar conta de tamanhas perdas e sobreviver à cultura.

\footnotetext{
${ }^{1}$ Benjamin (1994a) não quer, portanto, nem evocar o sujeito que se dissolveu e nem retornar à comunidade tradicional que se perdeu. Aliás, no texto "Experiência e pobreza", Benjamin (1994a) saúda a perda da tradição como possibilidade para o surgimento de algo novo: "Ela o impele a partir para frente, a começar de novo, a contentar-se com pouco, a construir com pouco, sem olhar nem para a direita nem para a esquerda. Segundo Benjamin (1994a), isto caracterizaria uma espécie de barbárie positiva, isto é, a possibilidade de um novo começo sem as limitações impostas pelo depauperamento da experiência".
} 
Nosso passeio pelo ensaio "Experiência e pobreza" será aqui interrompido para buscarmos em Adorno (2001) formas de pensar a experiência de ser professor na atualidade. Consideramos que esses autores se complementam ao abordar a temática da experiência e seus vínculos com a memória, com a história, com a arte de contar, com o passado, com a experiência.

\section{VIDA DANIFICADA E POBREZA DA EXPERIÊNCIA}

Vários foram os textos nos quais Adorno retoma o tema da experiência. Nesse texto, selecionamos alguns aforismos contidos nas "Minima Moralia" como objeto de reflexão e pensamento.

O processo de coisificação do homem mediado pela racionalidade instrumental e pela técnica que torna as pessoas semelhantes às máquinas é anotado por Adorno (2001) no aforismo "Devagar e sempre". O andar apressado das pessoas nas ruas, o culto à velocidade técnica, o esporte exacerbado, a reificação do pensamento configuram a produção da "nova subjetividade" na contemporaneidade. Talvez no culto das velocidades possibilitadas pela técnica - tal como no desporto - se esconda o impulso de dominar o horror de correr, separando este do próprio corpo e excedendo-o de um modo soberano: o triunfo do velocímetro a subir acalma ritualmente a angústia do perseguido. Mas se a uma pessoa se gritar - corre! - desde a criança, que deve ir buscar a bolsa que sua mãe esqueceu no primeiro andar, até ao prisioneiro, a quem o guarda ordena a fuga a fim de ter um pretexto para o matar, então ressoa a violência arcaica que, aliás, dirige silenciosa cada passo. (ADORNO, 2001, p. 165).

Nessas anotações, fica explicita a relação fetichizada do indivíduo com a técnica, canalizando a energia libidinal das pessoas e transformando-as para o apelo às máquinas, aos instrumentos, para o culto a uma eficiência que, ao privilegiar o meio, desconhece os fins. Aparece aqui a imagem do indivíduo ajustado, manipulável, transformado em mero objeto e sujeito à dominação. Adorno (2001) aponta para essa questão quando cita os comportamentos humanos, simples, mas que revelam, por exemplo, a ausência da consideração do outro, a decadência dos modos, uma prova de como a frieza está instalada nas relações humanas, tornando-as mais enfraquecidas e pobres. Limitados em si mesmos, os comportamentos humanos não provocam nenhuma experiência, pois retira do pensamento a reflexão necessária para que algo seja compreendido em toda sua complexidade.

Encontramos em "Sobre a Dialética do tato" o lamento de Adorno (2001) com relação aos comportamentos cotidianos, em que se evidencia a perda do tato, afirmando que a vida civilizada nos tornou rudes e rancorosos demais. Uma das observações anotadas por Adorno neste aforismo 
é uma denúncia daqueles elementos que tivemos que negar, de forma violenta, para nos tornarmos seres supostamente "adultos", "emancipados", "civilizados". Desse modo, o ser cortês, ser delicado hoje já não faz mais sentido numa sociedade marcada pela barbárie. A essa nova sensibilidade, gestada pelo avanço da técnica, não corresponde mais a experiência (Erfahrung), mas à vivência do choque.

Os indivíduos começam então, não sem motivo, a reagir hostilmente ao tato: uma certa forma de cortesia faz que eles não se sintam já considerados como homens, mas que neles desperte a suspeita da situação inumana em que se encontram [...]. (ADORNO, 2001, p. 31).

Adorno nos indica que a ausência de uma cultura formativa seria o elemento responsável pela semiformação e pela geração da barbárie. Dito de outro modo, a falta de formação impede o esclarecimento individual, inibe aquilo que ele chama de autorreflexão crítica.

\section{ALGUNS RESULTADOS DA PESQUISA}

Se refletirmos, sobretudo, na experiência de ser professor na atualidade ou de ser aluno, na experiência de estar inserido no contexto escolar, a experiência adquire um sentido de experiência "não vivida", "fragmentada", "isolada", pois aquilo que vivemos nesse ambiente não tem nada a ver conosco. Por intermédio de Larrosa (2002), acreditamos que a atividade docente poderia desenvolver a função de afetar o outro, o diferente. Para que ambos, professor e aluno, envolvidos numa experiência em que são afetados por ela, seja pela palavra, seja pela imagem apresentada, ou por um gesto, sejam afetados por intermédio de seus limites, suas finitudes, de seu inacabamento.

Estamos, pois, diante de uma reflexão a respeito das condições objetivas de possibilidade da experiência na escola e fora dela. Está em destaque elucidar como a experiência formativa pode ser um elemento de ressignificação do mal-estar que acomete aos professores na atualidade, pensando uma educação em função do qual o exercício autorreflexivo poderia ser recobrado no tempo presente. Buscamos dialogar com Adorno e Benjamin no sentido de entender como o mal-estar extrapola os bancos escolares, enquanto que concretamente, trata-se da mazela cotidiana e do massacre social do professor. Para nós, o mal-estar docente não se traduz simplesmente como uma "doença social". Para tanto, propomos outras leituras que ultrapassam as análises feitas pelos pesquisadores sobre a referida temática; Propomos uma discussão filosófica para a abordagem do tema mal-estar docente. 


\section{CONCLUSÃO}

Concluindo este artigo, procuramos mostrar em que medida tais momentos se relacionam com o processo educativo e formativo e com o processo de ressignificação do mal-estar vivenciado pelos docentes. Desse modo, além da ressignificação do fenômeno mal-estar docente pela via da experiência formativa, reivindicamos que o docente que o experimenta, resista subjetivamente às suas causas efetivas e potencialize essa atitude mediante o restabelecimento do sentido que a experiência oferece à sua ação.

\section{REFERÊNCIAS}

ADORNO, Theodor. Mínima Moralia: reflexões a partir da vida danificada. Tradução de Artur Morão. São Paulo: Edições 70, Ltda, , 2001.

BENJAMIN, Walter. Experiência e pobreza. In: Obras escolhidas I. Tradução de Sérgio Paulo Rouanet. São Paulo: Brasiliense, 1994a.

. O narrador: considerações sobre a obra de Nikolai Leskov. In: Obras escolhidas I. Tradução de Sergio Paulo Rouanet. São Paulo: Brasiliense, 1994b.

ESTEVE, José. M. O mal-estar docente: a sala de aula e a saúde dos professores. São Paulo: EDUSC, 1999.

FONSECA, Ana C. E. A. Contribuições da psicanalise a uma leitura do mal-estar docente na rede municipal de ensino em Olinda. 2009, 140 f. Dissertação (Mestrado em educação). Universidade Federal de Pernambuco, Recife/PE.

FREUD, Sigmund. (1930). O mal-estar na civilização. Rio de Janeiro: Imago, 1997.

GONÇALVES, Cecy, M. M. M. Escola Pública: bem-estar docente, mal-estar docente e gênero. 2008, 94 f. Dissertação (Mestrado em educação). Pontifícia Universidade Católica do Rio Grande do sul. Porto Alegre/RS.

KOBORI, Carolina. Organização e condições de trabalho de professoras - mal-estar docente $e$ permanência no emprego: estratégia defensiva? 2010, 120 f. Dissertação (Mestrado em educação). Universidade Estadual de Campinas. Campinas.

LAPO, Flavinês R. \& BUENO, Belmira. Professores: desencanto com a profissão e abandono do magistério. Cadernos de pesquisa, no 118, São Paulo, março 2003, p. 65-88.

LARROSA, Jorge. Notas sobre a experiência e o saber da experiência. Revista Brasileira de educação, no 19, São Paulo, jan./abr. 2002, p. 20-28.

LEAO, Cleri B. M. Entre o bem e o mal-estar docente: um retrato de professores do ensino superior privado. 2003, 102 f. Dissertação (mestrado em educação) 
NICHES, Cláudia C. Significados do mal-estar docente entre professores de história. 2010, $93 \mathrm{f}$. Dissertação (Mestrado em educação). Universidade do vale do Rio dos Sinos. São Leopoldo/RS.

RODRIGUES, Lenira S. Do mal-estar ao bem-estar docente: uma análise de caso Argentina e Brasil. 2011, 111 f. Dissertação (Mestrado em educação). Pontifícia Universidade Católica do Rio Grande do Sul-PUC-RS. Porto Alegre/RS.

SAMPAIO, Adelar A. Programa de apoio ao bem-estar docente: construção profissional e cuidar de si. 2008, 110 f. Dissertação (Mestrado em educação). Pontifícia Universidade Católica do Rio Grande do Sul. PUCRS, Porto Alegre.

STHEHL, Jussara M. Narrativas de professores sobre o mal-estar docente. 2010, 104 f. Dissertação (Mestrado em educação). Universidade do Passo Fundo. Passo Fundo.

WEBER, Sueli W. Uma investigação acerca dos fatores que contribuem para o mal-estar e o bemestar dos professores que trabalham com EAD. 2009, 170 f. Tese (Doutorado em educação). Pontifícia Universidade Católica do Rio Grande do Sul, PUCRS, Porto Alegre. 